\title{
LUBRICATION BY DIAMOND AND DIAMONDLIKE CARBON COATINGS
}

\author{
Kazuhisa Miyoshi \\ National Aeronautics and Space Administration \\ Lewis Research Center \\ Cleveland, Ohio 44135
}

\begin{abstract}
Regardless of environment (ultrahigh vacuum, humid air, dry nitrogen, or water), ion-beam-deposited diamondlike carbon (DLC) and nitrogen-ion-implanted, chemical-vapor-deposited (CVD) diamond films had low steady-state coefficients of friction $(<0.1)$ and low wear rates $\left(\leq 10^{-6} \mathrm{~mm}^{3} / \mathrm{N} \cdot \mathrm{m}\right)$. These films can be used as effective wear-resistant, self-lubricating coatings regardless of environment. On the other hand, as-deposited, fine-grain CVD diamond films; polished, coarse-grain CVD diamond films; and polished and then fluorinated, coarse-grain CVD diamond films can be used as effective wear-resistant, self-lubricating coatings in humid air, in dry nitrogen, and in water, but they had a high coefficient of friction and a high wear rate in ultrahigh vacuum. The polished, coarse-grain CVD diamond film revealed an extremely low wear rate, far less than $10^{-10} \mathrm{~mm}^{3} / \mathrm{N} \cdot \mathrm{m}$, in water.
\end{abstract}

\section{INTRODUCTION}

Presently, modern diamonds fall into four distinct categories: natural, high-pressure synthetic, chemical vapor deposited (CVD), and diamondlike carbon (DLC) (Pierson, 1993). In the last 100 years or so, the scarcity and high cost of natural diamond have been challenged by the large-scale production of synthetic diamond. Although highpressure synthetic and natural diamonds are used in the industrial market (particularly in wear and abrasive applications), their use in tribological applications is limited by small size and high cost (Gigl, 1989) and the need to be bonded to a substrate in a separate operation.

CVD diamond and DLC, the so-called new diamond materials, offer a broader potential than natural and highpressure synthetic diamonds because size and eventually cost will be less of a limitation. For example, CVD diamond has been uniformly deposited on a 20-cm-diameter area, and DLC has been deposited on a 200-cm-long knife-edge by a reactive-ion-plating technique (Murakawa, 1990). For large-area ( $>5 \mathrm{~mm}^{2}$ ) applications, CVD diamond and DLC are the only forms of diamond that seem economically viable. 
CVD diamond-film technology looks promising, although researchers are still tackling problems with enhancing adhesion to substrates (including steel), speeding up deposition (production) rates, and lowering costs (Feldman et al., 1995). CVD and DLC diamond films could edge into tribological and tooling applications. In NASA's perspective, diamond's excellent properties can suit it for coatings on tribological components and parts, such as valves and bearings in the harsh environment found in internal combustion and jet engines and in spacecraft. These films open the door to tribology technology and design engineering that can take full advantage of diamond's intrinsic properties in such areas as solid-lubricating, wear-resistant, erosion- and corrosion-resistant, and protective coatings. These materials offer lively new solutions to important engineering problems and exciting challenges to the tribologist or designer who seeks to exploit their cost-effective potential. Developing safe and economic applications for diamond materials that can compete with conventional tribological materials requires understanding their behavior and taking innovative approaches to manufacturing.

As-deposited CVD diamond film indeed has friction and wear properties similar to those of natural and synthetic diamonds in a variety of environments (Miyoshi et al., 1992, 1993). The tribological properties of the diamond materials, like those of conventional lubricating materials (e.g., graphite and molybdenum disulfide), vary with the environment, possessing a Jekyll-and-Hyde character. For example, diamond is one of the slipperiest materials, and is similar to polytetrafluoroethylene in terrestrial environments (Tabor, 1979; Bowden and Hanwell, 1966). However, when a fresh atomically, clean diamond surface contacts an atomically clean counterfacing material, strong bonds form between the two materials. In this case, diamond possesses high friction, low abrasion resistance, and low wear resistance (Tabor, 1979; Bowden and Hanwell, 1966; Miyoshi and Buckley, 1980). To some degree, this situation also applies to sliding contacts, where fresh surfaces are continuously exposed by the counterfacing material. Because direct contact with fresh surfaces is unavoidable under actual sliding conditions, the tribological performance of clean, unlubricated diamond is of paramount importance.

Getting the best performance from CVD diamond and DLC as solid-film lubricants and/or wear-resistant barriers for many moving mechanical assemblies requires a good understanding of CVD diamond and DLC themselves, the counterfacing materials, and the type of environment and operation. 
The investigation described herein examined the lubrication, friction, and wear properties of fine-grain CVD diamond films, surface-modified CVD diamond films, and ion-beam-deposited DLC films in four environments: humid air, dry nitrogen, ultrahigh vacuum, and water.

\section{MATERIALS}

The investigation encompassed four types of relatively smooth surfaces ( 6 to $37 \mathrm{~nm} \mathrm{rms}$ ) of as-deposited and surface-modified CVD diamond films: (1) as-deposited, fine-grain diamond; (2) polished, coarse-grain diamond; (3) polished and then fluorinated, coarse-grain diamond; and (4) polished and then nitrogen-ion-implanted, coarsegrain diamond. In addition, two types of smooth surfaces of ion-beam-deposited DLC films were investigated: (1) DLC deposited at an ion energy of $1500 \mathrm{eV}$ and (2) DLC deposited at an ion energy of $700 \mathrm{eV}$.

Wu et al. (1992a, 1993, 1995), Murakawa and Takeuchi (1991), and Miyake (1994) give details of CVD diamond and DLC deposition and modification techniques. Briefly, the as-deposited, fine-grain diamond films were produced on the flat surfaces of silicon, silicon nitride, and silicon carbide substrates by microwave-plasma-assisted chemical vapor deposition (Wu et al., 1992a). The polished, coarse-grain diamond films were produced on the flat surfaces of silicon nitride substrates by hot-filament chemical vapor deposition using a 1:100 mixture of methane $\left(\mathrm{CH}_{4}\right)$ and hydrogen $\left(\mathrm{H}_{2}\right)$ (Murakawa and Takeuchi, 1991). The fluorinated, coarse-grain diamond films were produced by exposing polished CVD diamond film to carbon tetrafluoride $\left(\mathrm{CF}_{4}\right)$ plasma using radiofrequency $(13.56 \mathrm{MHz})$ power at $1.3 \mathrm{~W} / \mathrm{cm}^{2}$ for $10 \mathrm{~min}$ and a flow rate of $10 \mathrm{ml} / \mathrm{min}$ at $8 \mathrm{~Pa}$ (Miyake, 1994). The nitrogen ion-implanted, coarse-grain diamond films were produced by impacting nitrogen ions into polished CVD diamond film using an accelerating energy of $35 \mathrm{keV}$, resulting in a dose of $5 \times 10^{16}$ ions $/ \mathrm{cm}^{2}$ in a calculated mean depth of $47 \mathrm{~nm}$ (Wu et al., 1993). The DLC films were deposited on silicon by the direct impact of an ion beam composed of a 3:17 mixture of argon (Ar) and $\mathrm{CH}_{4}$ at a radiofrequency power of $99 \mathrm{~W}$ and ion energies of $1500 \mathrm{or} 700 \mathrm{eV}$. DLC film thicknesses ranged from 520 to $660 \mathrm{~nm}$ (Wu et al., 1995). 


\section{EXPERIMENT}

A variety of analytical techniques was used to characterize CVD diamond and DLC films: scanning and transmission electron microscopy (SEM and TEM) to determine surface morphology and grain size and to study wear surfaces and wear debris; Rutherford backscattering spectroscopy (RBS) and hydrogen forward scattering to identify impurities (if any) in the films and to determine carbon and impurity concentrations; Raman spectroscopy and Fourier transform infrared spectroscopy (FTIR) to characterize carbon bonding and structure; $x$-ray photoelectron spectroscopy (XPS) to characterize surface chemistry; $\mathrm{x}$-ray diffraction to determine the crystal orientation; and surface profilometry and scanning probe microscopy to determine film surface morphology, roughness, and wear.

Unidirectional, rotating sliding friction experiments were performed at room temperature in humid air (40\% relative humidity), in dry nitrogen $\left(<1 \%\right.$ relative humidity), in ultrahigh vacuum $\left(10^{-7} \mathrm{~Pa}\right)$, and in distilled water. The friction apparatus used in the investigation was mounted in a chamber (Fig. 1). The apparatus can measure friction in a variety of environments including humid air, dry nitrogen, ultrahigh vacuum, and water. All experiments were conducted with CVD diamond, surface-modified CVD diamond, and DLC films in contact with CVD diamond pins (radius, $1.6 \mathrm{~mm}$ ) at a load of $0.49 \mathrm{~N}$ (a mean Hertzian contact pressure of approximately $2 \mathrm{GPa}$ ) and at a constant rotating speed of $120 \mathrm{rpm}$ (sliding velocity, 31 to $107 \mathrm{~mm} / \mathrm{s}$ depending on the range of wear track radii involved in the experiments). The friction force was continuously monitored during the friction experiments. Film wear volumes were obtained by measuring the average cross-sectional area determined from stylus tracings across the wear tracks at a minimum of eight locations in each track. Then, the average cross-sectional area of the wear track was multiplied by the wear track length. The wear rate, known as the dimensional wear coefficient, is defined as the volume of material removed at a unit applied load and in a unit sliding distance expressed as cubic millimeters per newton-meter.

\section{RESULTS}

\section{CVD Diamond and DLC Films}

Figure 2 presents typical Raman spectra of as-deposited, fine-grain CVD diamond film; surface-modified CVD diamond film; and as-deposited DLC film at ion energies of 1500 and $700 \mathrm{eV}$. In addition, Table I shows a comparison of some of their characteristics. 
The Raman spectrum of the as-deposited, fine-grain CVD diamond film contained the diamond form of $\mathrm{sp}^{3}$ bonded carbon at $1332 \mathrm{~cm}^{-1}$ as well as the G- and D-band nondiamond forms of carbon (Fig. 2(a)). The G-band Raman shifts are attributed to the $\mathbf{s p}^{2}$-bonded carbon, whereas the D-band Raman shifts are attributed to the disordered nondiamond carbon present in the CVD diamond film. Although the scattering efficiency of $\mathrm{sp}^{2}$-bonded carbon is more than 50 times that of $\mathrm{sp}^{3}$-bonded carbon (Wada and Solin, 1981), the as-deposited, fine-grain CVD diamond film actually contained much more of the latter (diamond) form of carbon than may be inferred from Figs. 2(a) to (c). However, the film also contained a considerable amount of nondiamond carbon. The film consisted of carbon, hydrogen, and some elements from the substrate material, such as silicon. The hydrogen concentration was estimated to be 2.5 at.\%. The film was primarily polycrystalline, the crystallites were oriented along the $\langle 110\rangle$ direction and had a granulated or spherulitic morphology, and the grain sizes ranged from 20 to $100 \mathrm{~nm}$. The surfaces contained spherical asperities ranging from 6 to $37 \mathrm{~nm}$ rms.

In comparison with the Raman spectrum of the as-deposited, fine-grain CVD diamond film, the Raman spectrum of the polished, coarse-grain CVD diamond film contained more of the diamond form of $\mathrm{sp}^{3}$-bonded carbon at $1332 \mathrm{~cm}^{-1}$ (Fig. 2(b)). The coarse-grain diamond film consisted primarily of carbon; the hydrogen concentration was estimated to be less than 1 at.\%. The film was primarily polycrystalline, the crystallites were oriented along the $\langle 111\rangle$ direction, and the grain size was approximately $10 \mu \mathrm{m}$. The mean surface roughness was $25 \mathrm{~nm}$ rms.

In comparison with the Raman spectra of the as-deposited, fine-grain and polished, coarse-grain CVD diamond films, the Raman spectrum of the fluorinated, coarse-grain CVD diamond film contained more of the diamond form of $\mathrm{sp}^{3}$-bonded carbon at $1332 \mathrm{~cm}^{-1}$ (Fig. 2(c)). The intensity of the sharp peak at $1332 \mathrm{~cm}^{-1}$, characteristic of the diamond form of $\mathrm{sp}^{3}$-bonded carbon, increased (in ascending order) for fine-grain diamond, polished diamond, and fluorinated diamond. The mean surface roughness of the fluorinated CVD diamond film was $8 \mathrm{~nm} \mathrm{rms}$. The surface morphology was almost the same as that of the polished CVD diamond film.

The nitrogen-ion-implanted, coarse-grain CVD diamond film contained primarily amorphous, nondiamond forms of carbon in its surface layer. The Raman spectrum (Fig. 2(d)) of this diamond film is quite different from those of the previous three CVD diamond films (Figs. 2(a) to (c)). It shows an extremely small characteristic diamond peak at $1332 \mathrm{~cm}^{-1}$ and a broad characteristic nondiamond carbon peak near $1530 \mathrm{~cm}^{-1}$. Nitrogen ion implantation produced a thin layer of amorphous, nondiamond carbon in the surface region of the coarse-grain CVD diamond film 
(Wu et al., 1993). The nitrogen ions penetrated to a calculated mean depth of $47 \mathrm{~nm}$, and the mean surface roughness was $6 \mathrm{~nm}$ rms. The surface morphology was almost the same as that of the polished CVD diamond film.

The DLC films contained primarily amorphous, nondiamond carbon. The characteristic diamond peak is absent from the micro-Raman spectra of the ion-beam-deposited DLC films (Figs. 2(e) and (f)). The graphitic $\mathrm{sp}^{2}$-bonded carbon (G-band) peak is sharper and the disordered nondiamond carbon (D-band) is more prevalent in the Raman spectrum of the DLC film deposited at $1500 \mathrm{eV}$ than in that of the DLC film deposited at $700 \mathrm{eV}$. The hydrogen concentration was lower in the DLC film deposited at $1500 \mathrm{eV}$ than in that deposited at $700 \mathrm{eV}$. The compositions of the DLC films deposited at 1500 and $700 \mathrm{eV}$ were, in atomic percent, $\mathrm{C}_{59} \mathrm{H}_{36} \mathrm{Ar}_{1.8}$ and $\mathrm{C}_{57} \mathrm{H}_{42} \mathrm{Ar}_{0.8}$, respectively. The ratio of carbon to hydrogen for the DLC film deposited at $1500 \mathrm{eV}$ was 1.64 ; that for the DLC film deposited at $700 \mathrm{eV}$ was 1.36 . The mean surface roughnesses of the DLC films deposited at 1500 and $700 \mathrm{eV}$ were 22 and $14 \mathrm{~nm}$ rms, respectively.

\section{Coefficients of Friction and Wear Rates}

Figure 3 presents the steady-state (equilibrium) coefficients of friction and wear rates at room temperature in humid air ( $40 \%$ relative humidity), in dry nitrogen ( $<1 \%$ relative humidity), in an ultrahigh vacuum $\left(10^{-7} \mathrm{~Pa}\right)$, and in water for the same films as in Fig. 2. For a direct comparison, the coefficients of friction and the wear rates were plotted from 0.01 to 1 and from $10^{-10}$ to $10^{-3} \mathrm{~mm}^{3} / \mathrm{N} \cdot \mathrm{m}$, respectively. An effective wear-resistant, self-lubricating material must generally have a coefficient of friction less than 0.1 and a wear rate less than $10^{-6} \mathrm{~mm}^{3} / \mathrm{N} \cdot \mathrm{m}$.

The results presented in Fig. 3 indicate that both the steady-state coefficients of friction and wear rates of the CVD diamond and DLC films depended on the environment. Conditions that reduced friction, such as a particular combination of environment and material, usually reduced wear rate as well.

The as-deposited, fine-grain CVD diamond film (Fig. 3(a)) had a low coefficient of friction $(<0.1)$ and a low wear rate (order of $10^{-6} \mathrm{~mm}^{3} / \mathrm{N} \cdot \mathrm{m}$ ) in three environments: humid air, dry nitrogen, and water. However, in ultrahigh vacuum it had a high coefficient of friction $(>0.1)$ and a high wear rate (order of $10^{-4} \mathrm{~mm}^{3} / \mathrm{N} \cdot \mathrm{m}$ ), which are not acceptable for solid-film lubrication applications. In an ultrahigh vacuum, removing some contaminant surface film from the contact area resulted in stronger interfacial adhesion between the diamond pin and the diamond films and 
raised the coefficient of friction, and accordingly, the wear rate. These results are consistent with previous results (Miyoshi et al., 1993). The increase in friction and wear was attributed to removing the adsorbed contaminants from the surface by sliding in an ultrahigh vacuum at room temperature.

Like the as-deposited, fine-grain CVD diamond film, the polished, coarse-grain CVD diamond film (Fig. 3(b)) had low friction and wear in humid air, dry nitrogen, and water and high friction and wear in ultrahigh vacuum. Interestingly, the polished, coarse-grain CVD diamond film revealed an extremely low wear rate, far less than $10^{-10} \mathrm{~mm}^{3} / \mathrm{N} \cdot \mathrm{m}$, in water.

The fluorinated, coarse-grain CVD diamond film (Fig. 3(c)) also had friction and wear properties similar to those of the as-deposited, fine-grain diamond film and the polished, coarse-grain diamond film: low in humid air, dry nitrogen, and water and high in ultrahigh vacuum.

The nitrogen ion-implanted CVD diamond film (Fig. 3(d)) had low friction and wear, regardless of environment. This result is consistent with the friction and wear properties of carbon-ion-implanted CVD diamond film (Wu et al., 1993; Miyoshi, 1995a). The effect of ion implantation on friction and wear is discussed later under Mechanism of Lubrication. Similar to the nitrogen-ion-implanted diamond film, the DLC films deposited at both 1500 - and $700-\mathrm{eV}$ ion energy (Figs. 3(e) and (f)) had a low coefficient of friction $(<0.1)$ and a low wear rate $\left(\leq 10^{-6} \mathrm{~mm}^{3} / \mathrm{N} \cdot \mathrm{m}\right)$ regardless of environment.

\section{Wear Behavior}

SEM observations (Fig. 4) indicate that wear debris particles (submicrometer to micrometer in size) were generated by sliding action on the surfaces of the diamond films, the DLC films, and the diamond pins. Much finer particles were generated on the surfaces of the nitrogen-ion-implanted diamond films and the ion-beam-deposited DLC films than on the surfaces of the as-deposited, fine-grain diamond; polished, coarse-grain diamond; and fluorinated, coarse-grain diamond films. These finer particles primarily resulted from the wear and removal of amorphous, nondiamond carbon by sliding. 


\section{DISCUSSION}

\section{Mechanism of Lubrication}

The Bowden-Tabor model of metallic friction provides a starting point for understanding how CVD diamond and DLC films can reduce friction (Bowden and Tabor, 1964; Singer, 1992). If the plowing contribution in friction is neglected, the friction arising between the films and a CVD diamond pin is described by the equation $\mu=s A / W$ (Bowden and Tabor, 1964) or $\mu \propto \gamma A$ (Miyoshi, 1995b) because the surfaces of fine-grain CVD diamond, surfacemodified CVD diamond, and ion-beam-deposited DLC films are smooth. In these equations, $\mu$ is the coefficient of friction, $s$ is the shear strength of the contact area (junction), $A$ is the true contact area, $W$ is the normal contact load, and $\gamma$ is the surface energy.

Figure 5 illustrates how the friction and the surface condition can vary with the material and the environment. With adsorbed contaminants (water vapor, carbon oxides, and hydrocarbons usually about 2 nm thick), the hard diamond film provided a small contact area $A$, minimized penetration of the diamond pin (accordingly, plowing will be negligible), and either reduced the shear strength $s$ or maintained the low surface energy $\gamma$ of the contact area

(Fig. 5(a)). When the model of dangling carbon bonds of diamond (Gardos, 1994; Holmberg, 1993) was applied to Fig. 5(a), these bonds could be terminated with surface contaminants (hydrogen, hydroxyl groups, and organic radicals on CVD diamond films and high-pressure synthetic diamonds), providing a low friction in terrestrial (or nonvacuum) environments. For these reasons, the coefficients of friction for the as-deposited, fine-grain diamond films; the polished, coarse-grain diamond films; and the fluorinated, coarse-grain diamond films studied in this investigation were low in humid air and in dry nitrogen.

Removing some of the contaminant surface layers from the contact area (Fig. 5(b)) resulted in stronger interfacial adhesion between the diamond pin and the diamond film and accordingly raised the coefficient of friction. Contaminant surface layers were removed by repeatedly sliding the pin over the same track in ultrahigh vacuum. The hard diamond film provided a small contact area $A$ and minimized penetration of the diamond pin (accordingly, plowing will be negligible). Removing adsorbates (contaminant layers) from the contact area enhanced adhesion and increased either the shear strength $s$ or the surface energy $\gamma$ of the contact area. When the model of dangling carbon bonds (Gardos, 1994; Holmberg, 1993) was applied to Fig. 5(b), these bonds formed a strong carbon-carbon bonds, 
providing high friction in a space or vacuum environment. For these reasons, the steady-state coefficients of friction for the as-deposited, fine-grain diamond films; the polished, coarse-grain diamond films; and the fluorinated, coarsegrain diamond films were extremely high in ultrahigh vacuum.

Figures 5(c) and (d) represent the case of the nitrogen-ion-implanted, coarse-grain CVD diamond film in sliding contact with a diamond pin. The ion implantation processes produced a thin surficial layer $(<0.1 \mu \mathrm{m}$ thick) of amorphous, nondiamond carbon on the diamond film. This surface layer had low shear strength $s$ or low surface energy $\gamma$ at the contact area. Further, because the nondiamond carbon surface layer was thin enough $(<0.1 \mu \mathrm{m})$, the true contact area resulting from the high elastic modulus and hardness of the underlying diamond, which largely supported the applied load, was small. In general, the combination of either low shear strength or low surface energy of the thin, nondiamond carbon surface layer and the small contact area gave low coefficients of friction $(<0.1)$ for the nitrogen-ion-implanted CVD diamond regardless of environment. Thus, disordering the diamond surface with ion implantation created self-lubricating surface conditions on diamond regardless of the environment.

Because the contaminant layer, coupled with a nondiamond carbon surface layer, provided low shear strength $s$ or low surface energy $\gamma$ at the contact area, the nitrogen-ion-implanted, coarse-grain diamond film had a low coefficient of friction $(\sim 0.1)$ and a low wear rate $\left(10^{-7} \mathrm{~mm}^{3} / \mathrm{N} \cdot \mathrm{m}\right)$ in humid air and in dry nitrogen (Fig. 5(c)). However, nitrogen ion implantation had little effect on the coefficients of friction in humid air and dry nitrogen, since thin contaminant layers (such as adsorbed gases, water vapor, and hydrocarbons) are present on every surface of any solid once exposed to air. On the other hand, in ultrahigh vacuum (Fig. 5(d)), nitrogen ion implantation greatly reduced the coefficient of friction and greatly increased the wear resistance. In ultrahigh vacuum, the presence of the nondiamond carbon layer on the fine-grain diamond films reduced the coefficient of friction to $\leq 0.1$ and the wear rate to $10^{-6} \mathrm{~mm}^{3} / \mathrm{N} \cdot \mathrm{m}$, which are acceptable for tribological applications. Thus, the nitrogen-ion-implanted, finegrain diamond film is an effective self-lubricating, wear-resistant coating, not only in air and in dry nitrogen but in ultrahigh vacuum as well.

Figures 5(e) and (f) represent the case of the ion-beam-deposited DLC film in sliding contact with a CVD diamond pin. The hydrogenated surface of the DLC film had low shear strength $s$ or low surface energy $\gamma$ (with or without adsorbed contaminants) at the contact area. Further, the true contact area resulting from the relatively high Vickers hardness $(\sim 1500)$ of the hydrogenated carbon surface, which largely supported the applied load, was small. 
Therefore, the coefficients of friction for the ion-beam-deposited DLC film were low $(<0.1)$ regardless of environment. The most important element to be considered in the cases shown in Figs. 5(e) and (f) is hydrogen. When DLC films contain no hydrogen or only a small amount of hydrogen, they provide a graphite-like friction behavior (i.e., a low coefficient of friction in a humid environment and a high coefficient of friction in dry, vacuum, or space environments (Miyoshi et al., 1989, 1991; Wu et al., 1992b; Eldemir et al., 1993; Zaidi et al., 1994; Voevodin et al., 1996; Liu et al., 1996).

A disadvantage of ion implantation technology is that the penetration depth of implanted species is shallow $(0.01$ to $0.5 \mu \mathrm{m})$ relative to that of conventional coatings. This shallow penetration may limit the wear life expectancy of the ion-implanted layer and hence limit tribological applications to light-load or short-term operations. On the other hand, ion-beam deposition makes it possible to produce uniform DLC films that are a few micrometers thick on large areas and curved surfaces. This greater range of DLC coating thickness, coupled with low friction and wear, regardless of environment, can lead to a longer endurance (wear) life expectancy and better wear resistance than those of carbon-ion-implanted CVD diamond films. For example, the endurance life of DLC films with a coating thickness of $0.5 \mu \mathrm{m}$ on CVD diamond is approximately 20 times greater than that of carbon-ion-implanted, fine-grain CVD diamond with an amorphous, nondiamond 0.05- $\mu$ m-thick carbon layer (Miyoshi, 1995a). Thus, the DLC film is also an effective wear-resistant, self-lubricating carbon film regardless of environment.

\section{Mechanism of Wear}

The mechanism of wear for the CVD diamond and DLC films studied in this investigation was an adhesive interaction that caused small fragments (submicrometer to micrometer size) to be removed from the surfaces of both the CVD diamond pin and the CVD diamond or DLC film (e.g., Fig. 4). Much finer wear particles were generated on the surfaces of the DLC film and the nitrogen-ion-implanted CVD diamond film than on the surfaces of the as-deposited CVD diamond, polished CVD diamond, or fluorinated CVD diamond films. The size of the wear particles generally correlated with the film wear rate: the larger the wear particle, the higher the wear rate. 


\section{CONCLUSIONS}

From the results of characterization and sliding friction experiments on as-deposited, fine-grain, chemical-vapordeposited (CVD) diamond films; polished, coarse-grain CVD diamond films; fluorinated, coarse-grain CVD diamond films; nitrogen-ion-implanted, coarse-grain CVD diamond films; and ion-beam-deposited amorphous diamondlike carbon (DLC) films in four environments (humid air, dry nitrogen, ultrahigh vacuum, and water), the following conclusions were drawn:

1. The ion-beam-deposited DLC and the nitrogen-ion-implanted CVD diamond films can be used as effective wear-resistant, self-lubricating coatings regardless of environment.

2. As-deposited, fine-grain CVD diamond; polished, coarse-grain CVD diamond; and fluorinated, coarse-grain CVD diamond films can be used as effective wear-resistant, self-lubricating coatings in humid air, dry nitrogen, and water, although they have a high coefficient of friction and a high wear rate in ultrahigh vacuum.

3. The polished, coarse-grain CVD diamond film has an extremely low wear rate of less than $10^{-10} \mathrm{~mm} / \mathrm{N} \cdot \mathrm{m}$ in water.

\section{ACKNOWLEDGMENTS}

The author would like to thank Drs. R.L.C. Wu, W.C. Lanter, A. Garscadden, P.N. Barnes, and Susan L. Heidger of Wright Laboratory, Wright-Patterson Air Force Base, Ohio, for producing the as-deposited diamond and DLC films and for the Raman analysis; and Drs. M. Murakawa, S. Miyake, S. Watanabe, and S. Takeuchi of Nippon Institute of Technology for producing the surface-modified diamond films.

\section{REFERENCES}

Bowden, F.P., and Hanwell, A.E., 1966, “The Friction of Clean Crystal Surfaces," Proceeding of Royal Society London Series A, Vol. 295, pp. 233-243.

Bowden, F.P., and Tabor, D., 1964, "The Friction and Lubrication of Solids, Pt. 2. Clarendon, Oxford.

Eldimir, A., et al., 1993, "Friction and Wear Performance of Ion-Beam-Deposited Diamond-like Carbon Films on Steel Substrates," Diamond and Related Materials, Vol. 3, pp. 119-125. 
Feldman, A., et al., eds., 1995, Applications of Diamond Films and Related Materials, Proceedings of the Third International Applied Diamond Conference, National Institute of Standards and Technology, No. 885.

Gardos, M., 1994, "Tribology and Wear Behavior of Diamond," Synthetic Diamond: Emerging CVD Science and Technology, John Wiley \& Sons, Inc., pp. 419-502.

Gigl, P.D., 1989, “New Synthesis Techniques: Properties and Applications for Industrial Diamond," presented at the IDA Ultrahard Materials Seminar, Toronto, Ontario, Canada, Sept. 27.

Holmberg, K., 1993, "Tribology of Diamond and Diamond Coatings, a Review," Tribologia, Finnish Journal of Tribology, Vol. 12, No. 4, pp. 33-62.

Liu, Y., Erdemir, A., and Meletis, E.I., 1996, “A Study of the Wear Mechanism of Diamond-like Carbon Films,” Surface and Coatings Technology, Vol. 82, pp. 48-56.

Miyake, S., 1994, “Tribological Improvements of Polished Chemically Vapor Deposited Diamond Films by Fluorination," Applied Physics Letters, Vol. 65, No. 9, pp. 1109-1111.

Miyoshi, K., 1995a, "Wear-Resistant, Self-lubricating Surfaces of Diamond Coatings," Feldman, A., et al., eds., 1995, Applications of Diamond Films and Related Materials, Proceedings of the Third International Applied Diamond Conference, National Institute of Standards and Technology, No. 885, pp. 493-500.

Miyoshi, K., 1995b, “Adhesion, Friction, and Wear Behavior of Clean Metal-Ceramic Couples," NASA TM-106815, and also 1996, Proceedings of the International Tribology Conference, Yokohama 1995, Vol. III Japanese Society of Tribologists, Tokyo, Japan, pp. 1853-1858.

Miyoshi, K., et al., 1993, "Friction and Wear of Plasma-Deposited Diamond Films, Journal of Applied Physics, Vol. 74, No. 7, pp. 4446-4454. (Also NASA TM-105926.)

Miyoshi, K., Wu, R.L.C., and Garscadden, A., 1992, “Friction and Wear of Diamond and Diamondlike Carbon Coatings," Surface Coating Technology, Vol. 54/55, pp. 428-434.

Miyoshi, K., 1991, "Friction and Wear of Plasma-Deposited Amorphous Hydrogenated Films on Silicon Nitride," Advanced Information and Storage Systems, Vol. 3, pp. 147-160.

Miyoshi, K., Pouch, J.J., and Alterovitz, S.A., 1989, “Plasma-Deposited Amorphous Hydrogenated Carbon Films and Their Tribological Properties," Material Science Forum, Vols. 52 \& 53, pp. 645-656. 
Miyoshi, K., and Buckley, D.H., 1980, “Adhesion and Friction of Single-Crystal Diamond in Contact With Transition Metals," Applied Surface Science, Vol. 6, pp. 161-172.

Murakawa, M., and Takeuchi, S., 1991, "Forming of a Grinding Wheel Using a Dresser With Brazed Diamond Films," Materials Science Engineering, Vol. A140, pp. 759-763.

Murakawa, M., 1990, "Film Growth Technologies for Superhard Coatings and Their Application to Tools," Journal of Japanese Society of Tribologists, Vol. 35, No. 6, pp. 392-397.

Pierson, H.O., 1993, Handbook of Carbon, Graphite, Diamond, and Fullerenes: Properties, Processing, and Applications, Noyes Publications.

Singer, I.L., 1992, “Solid Lubrication Processes," Proceedings of NATO Advanced Study Institute on Fundamental of Friction, I.L. Singer and H.M. Pollock, eds., Kluwer Academic Publishers, Dordrecht, pp. 237-261.

Tabor, D., 1979, “Adhesion and Friction," Properties of Diamond, J.E. Field, ed., Academic Press, New York, 1979, pp. $325-350$.

Voevodin, A.A., et al., 1996, "Friction-Induced Phase Transformation of Pulsed-Laser-Deposited Diamond-Like Carbon," Diamond and Related Materials, Vol. 5, pp. 1264-1269.

Wada, N., and Solin, S.A., 1981, "Raman Efficiency Measurements of Graphite," Physica, 105 B \& C, pp. 353-356.

Wu, R.L.C., et al., 1995, "Uniform and Large Area Deposition of Diamond-like Carbon Using RF Source Ion Beam," Proceedings of Materials Research Society Symposium, Vol. 354, pp. 63-68.

Wu, R.L.C., et al., 1993, "Tribological and Physical Properties of Ion-Implanted Diamond Films," Diamond Films and Technology, Vol. 3, No. 1, pp. 17-29.

Wu, R.L.C., et al., 1992a, Synthesis and Characterization of Fine Grain Diamond Films, Journal of Applied Physics, Vol. 72 , No. 1, pp. 110-116.

Wu, R.L.C., et al., 1992b, "Physical and Tribological Properties of Rapid Thermal Annealed Diamond-like Carbon Films, Surface and Coating Technology, Vol. 54/55, pp. 576-580.

Zaidi, H., Le Huu, T., and Paulmier, D., 1994, "Influence of Hydrogen Contained in Hard Carbon Coatings on Their Tribological Behavior," Diamond and Related Materials, Vol. 3, pp. 787-790. 
TABLE I.-COMPARISON OF CHARACTERISTICS OF DIAMOND AND DLC FILMS

\begin{tabular}{|l|c|c|l|c|}
\hline \multicolumn{1}{|c|}{ Surface type } & $\begin{array}{c}\text { rms surface } \\
\text { roughness, } \\
\mathrm{nm}\end{array}$ & $\begin{array}{c}\text { Grain size, } \\
\mathrm{nm}\end{array}$ & \multicolumn{1}{|c|}{ Microstructure } & $\begin{array}{c}\text { Dominated } \\
\text { crystal } \\
\text { orientation }\end{array}$ \\
\hline $\begin{array}{l}\text { As-deposited, fine-grain } \\
\text { diamond }\end{array}$ & 6 to 37 & 20 to 100 & Polycrystalline & $\langle 110\rangle$ \\
\hline $\begin{array}{l}\text { Polished, coarse-grain } \\
\text { diamond }\end{array}$ & 25 & 10000 & Polycrystalline & $\langle 111\rangle$ \\
\hline $\begin{array}{l}\text { Fluorinated, coarse-grain } \\
\text { diamond }\end{array}$ & 8 & 10000 & Polycrystalline & $\langle 111\rangle$ \\
\hline $\begin{array}{l}\text { Nitrogen-ion-implanted, } \\
\text { coarse-grain diamond }\end{array}$ & 6 & 10000 & $\begin{array}{l}\text { Layered structure-amorphous } \\
\text { carbon layer on crystalline diamond }\end{array}$ & $\langle 111\rangle$ \\
\hline DLC deposited at $1500 \mathrm{eV}$ & 22 & ---- & Amorphous & ---- \\
\hline DLC deposited at $700 \mathrm{eV}$ & 14 & ---- & Amorphous & ---- \\
\hline
\end{tabular}




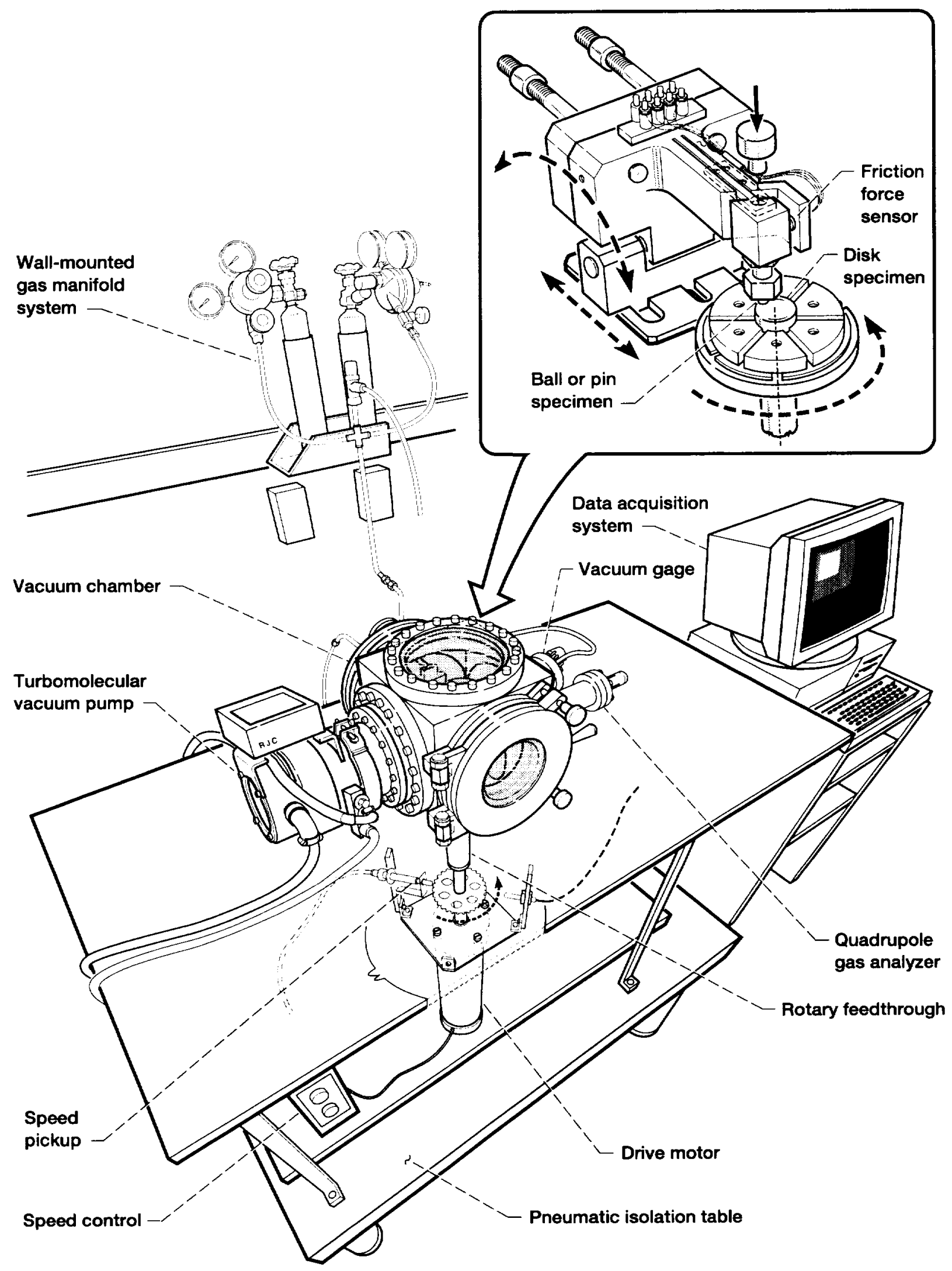

Figure 1.-Chamber tribometer. 

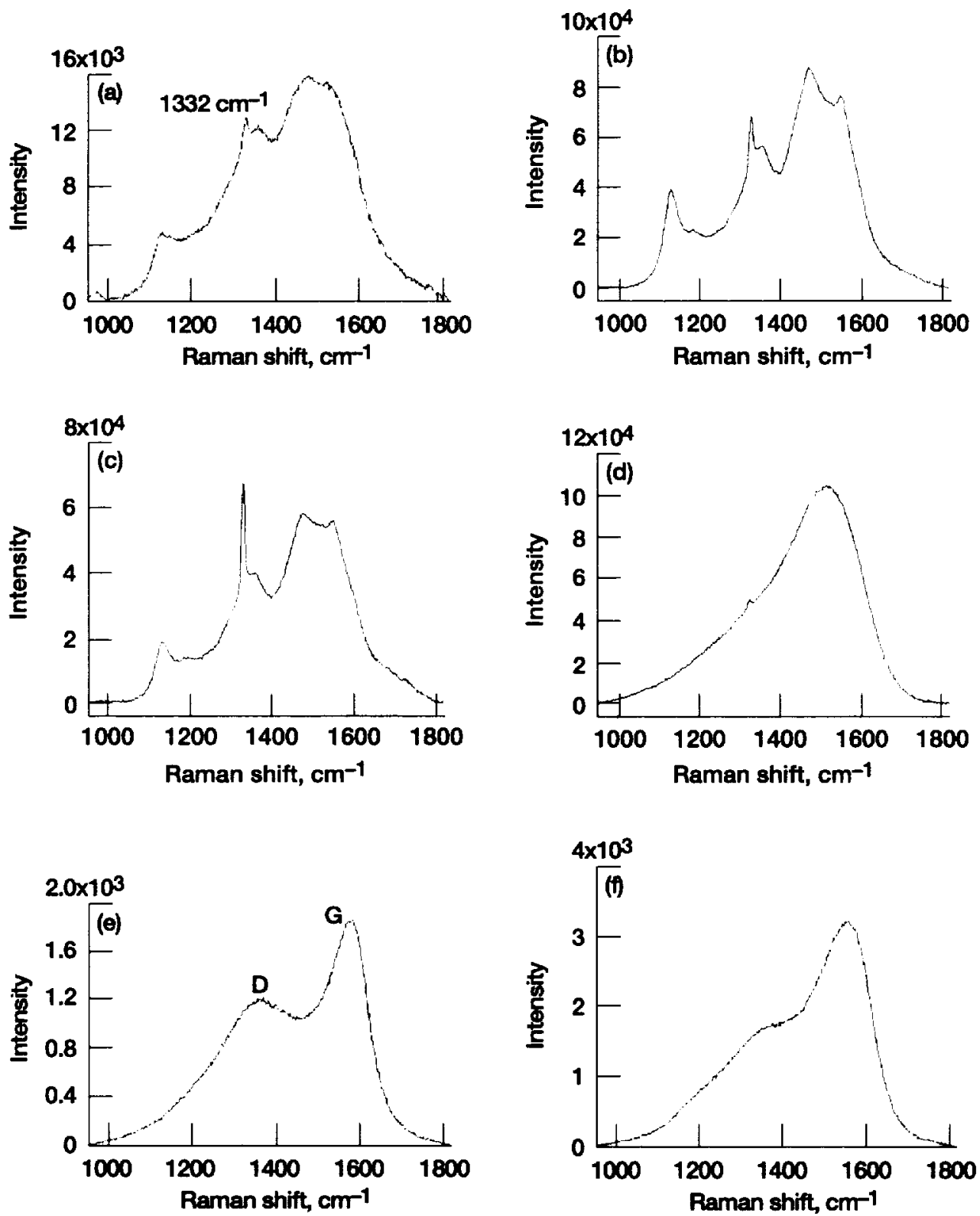

Figure 2.-Raman spectra. (a) As-deposited, fine-grain diamond film. (b) Polished, coarse-grain diamond film. (c) Fluorinated, coarse-grain diamond film. (d) Nitrogen-ionimplanted, coarse-grain diamond film. (e) Diamondlike carbon film at ion energy of $1500 \mathrm{eV}$. (f) Diamondlike carbon film at ion energy of $700 \mathrm{eV}$. 

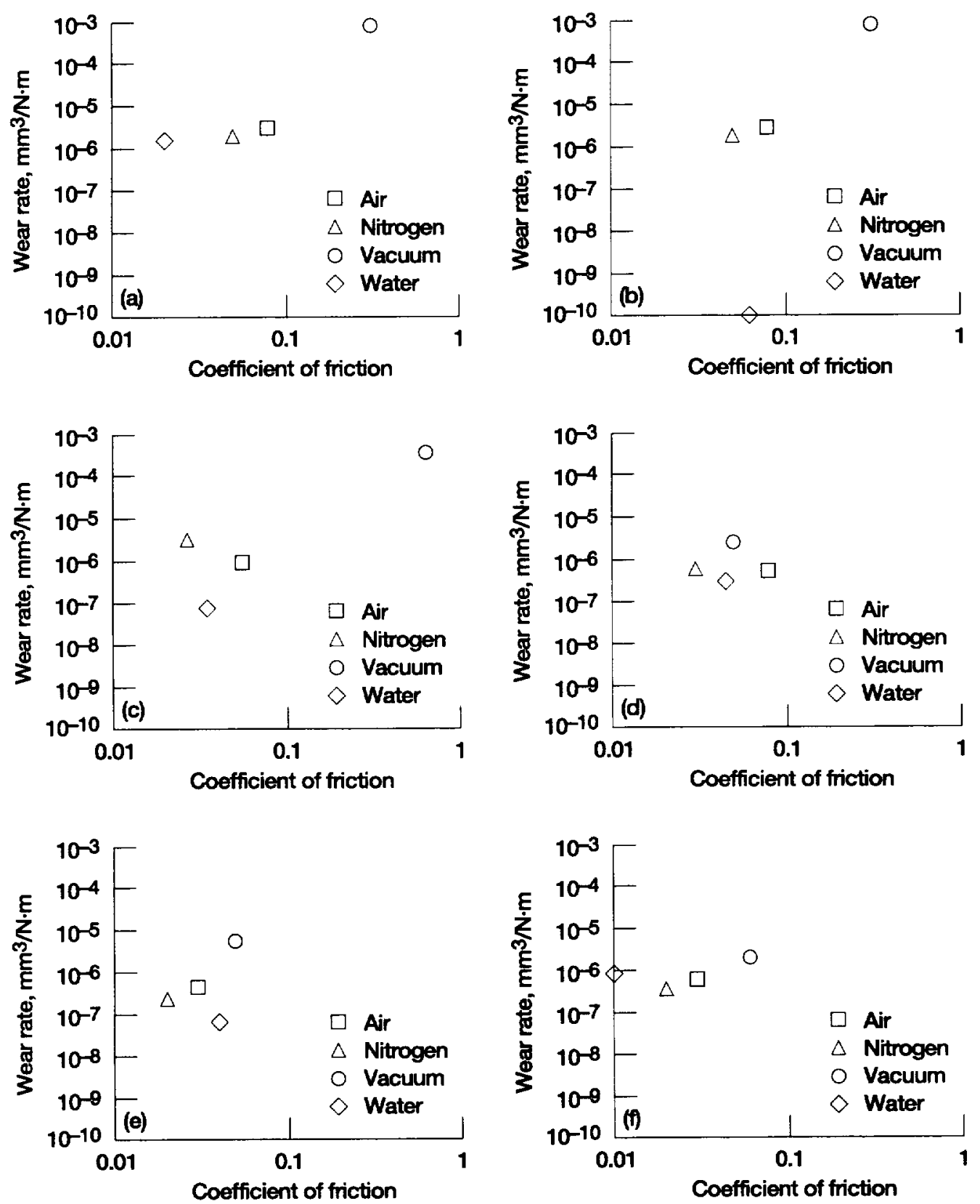

Figure 3.-Coefficients of friction and wear rates of various films in sliding contact with CVD diamond pins in humid air, dry nitrogen, ultrahigh vacuum, and water. (a) As-deposited, finegrain diamond film. (b) Polished, coarse-grain diamond film. (c) Fluorinated, coarse-grain diamond film. (d) Nitrogen-ion-implanted, coarse-grain diamond film. (e) Diamondlike carbon film at ion energy of $1500 \mathrm{eV}$. (f) Diamondlike carbon film at ion energy of $700 \mathrm{eV}$. 

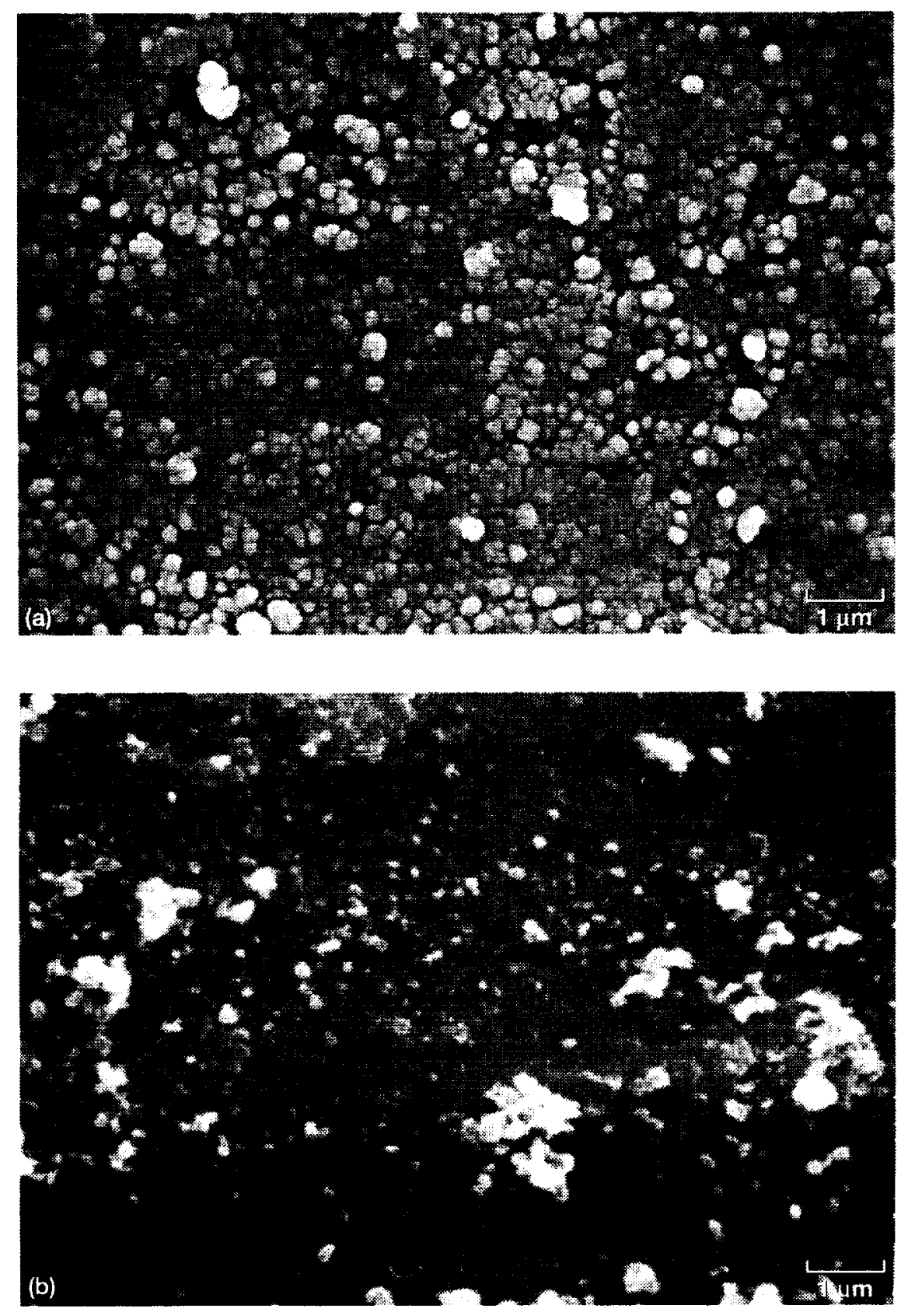

Figure 4.- Scanning electron micrographs of wear debris particles produced on (a) as-deposited, fine-grain CVD diamond film and (b) lon-beam-deposited DLC film after sliding against diamond pins in ultrahigh vacuum. 

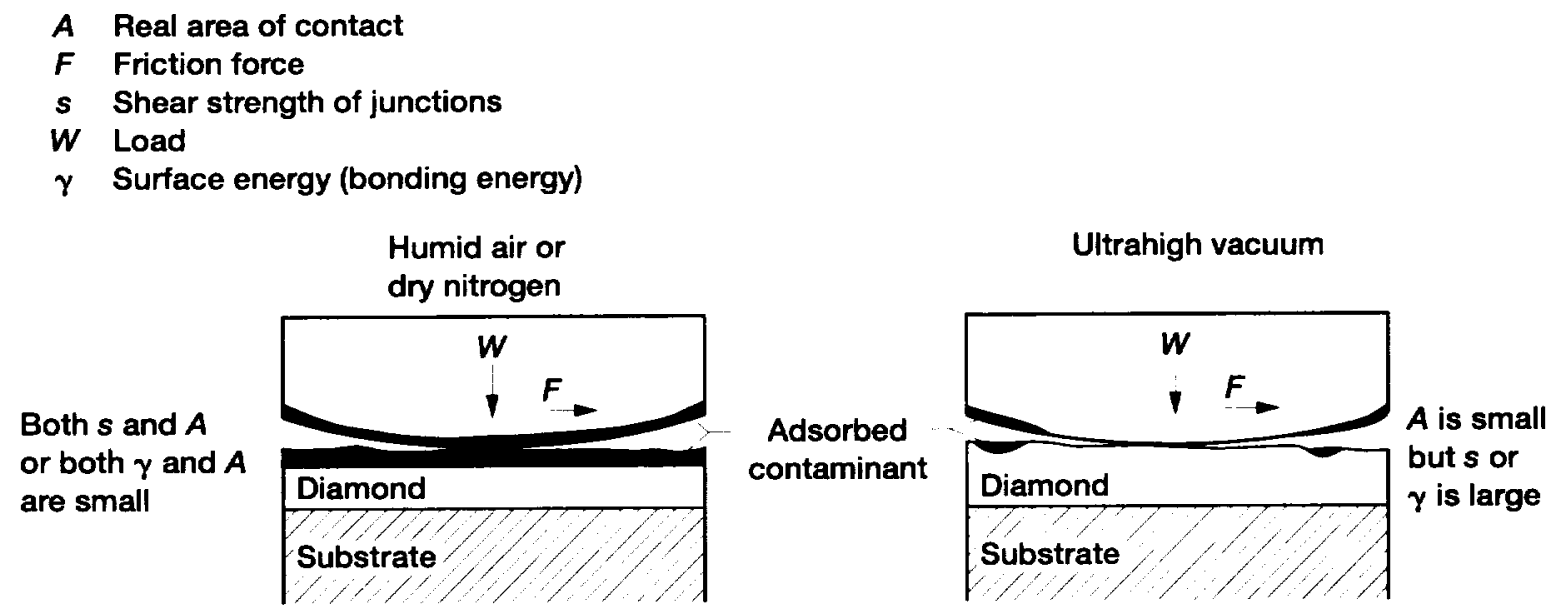

(a)

(b)

Both $s$ and $A$ or both $\gamma$ and $A$ are small

(c)

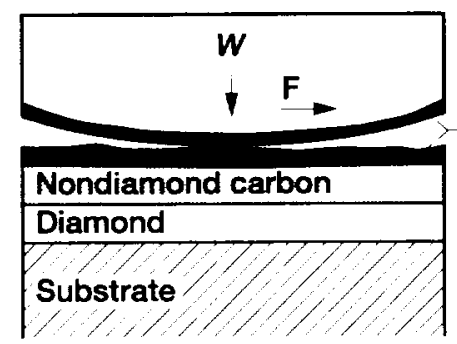

Both $s$ and $A$ or both $\gamma$ and $A$ are small

(e)

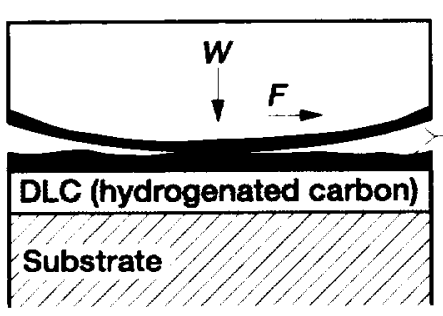

Adsorbed contaminant

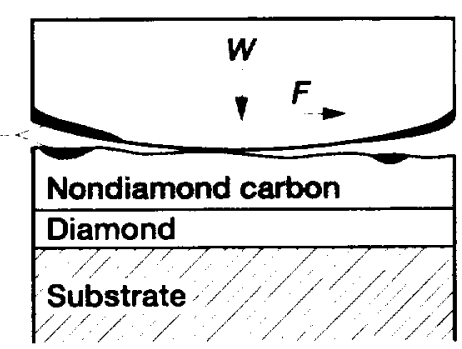

(d)

Both $s$ and $A$ or both $\gamma$ and $A$ are small
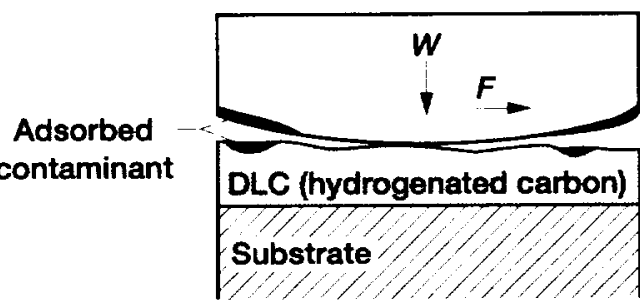

Both $s$ and $A$ or both $\gamma$ and $A$ are small

(f)

Figure 5.-Contact between pin and film in humid air, dry nitrogen, and ultrahigh vacuum. (a) and (b) Asdeposited, fine-grain diamond film; polished, coarse-grain diamond film; and fluorinated, coarse-grain diamond film. (c) and (d) Nitrogen ion-implanted, coarse-grain diamond film. (e) and (f) Diamondlike carbon film. 
Public reporting burden for this collection of information is estimated to average 1 hour per response, including the time for reviewing instructions, searching existing data sources, gathering and maintaining the data needed, and completing and reviewing the collection of intormation. Send comments regarding this burden estimate of any other aspect of this collection of information, including suggestions for reducing this burden, to Washington Headquaners Services, Directorate for Information Operations and Reports, 1215 Jefferson Davis Highway, Suite 1204, Arlington, VA 22202-4302, and to the Otfice of Management and Budget, Paperwork Peduction Project (0704-0188), Washington, DC 20503.

\begin{tabular}{l|l} 
1. AGENCY USE ONLY (Leave blank) & 2. REPORT DATE
\end{tabular}

June 1997

3. REPORT TYPE AND DATES COVERED

\section{TITLE AND SUBTITLE}

Lubrication by Diamond and Diamondlike Carbon Coatings

6. AUTHOR(S)

Kazuhisa Miyoshi

7. PERFORMING ORgANIZATION NAME(S) AND ADDRESS(ES)

National Aeronautics and Space Administration

Lewis Research Center

Cleveland, Ohio 44135-3191

9. SPONSORINGMONITORING AGENCY NAME(S) AND ADDRESS(ES)

National Aeronautics and Space Administration

Washington, DC 20546-0001
Technical Memorandum

WU-505-63-5A

8. PERFORMING ORGANIZATION REPORT NUMBER

E-10462

10. SPONSORINGMONITORING AGENCY REPORT NUMBER

NASA TM-107472

\section{SUPPLEMENTARY NOTES}

Prepared for the Tribology Conference sponsored by the American Society of Mechanical Engineers, London, United Kingdom, September 8-12, 1997. Responsible person, Kazuhisa Miyoshi, organization code 5140, (216) 433-6078.

12a. DISTRIBUTION/AVAILABILTTY STATEMENT

12b. DISTRIBUTION CODE

Unclassified - Unlimited

Subject Category 27

This publication is available from the NASA Center for AeroSpace Information, (301) 621-0390.

13. ABSTRACT (Maximum 200 words)

Regardless of environment (ultrahigh vacuum, humid air, dry nitrogen, or water), ion-beam-deposited diamondlike carbon (DLC) and nitrogen-ion-implanted, chemical-vapor-deposited (CVD) diamond films had low steady-state coefficients of friction $(<0.1)$ and low wear rates $\left(\leq 10^{-6} \mathrm{~mm}^{3} / \mathrm{N} \cdot \mathrm{m}\right)$. These films can be used as effective wear-resistant, self-lubricating coatings regardless of environment. On the other hand, as-deposited, fine-grain CVD diamond films; polished, coarsegrain CVD diamond films; and polished and then fluorinated, coarse-grain CVD diamond films can be used as effective wear-resistant, self-lubricating coatings in humid air, in dry nitrogen, and in water, but they had a high coefficient of friction and a high wear rate in ultrahigh vacuum. The polished, coarse-grain CVD diamond film revealed an extremely low wear rate, far less than $10^{-10} \mathrm{~mm}^{3} / \mathrm{N} \cdot \mathrm{m}$, in water.

\begin{tabular}{|c|c|c|}
\hline $\begin{array}{l}\text { 14. SUBJECT TERMS } \\
\text { Diamond and DLC coatir }\end{array}$ & s; Lubrication; Tribology & \\
\hline $\begin{array}{l}\text { 17. SECURITY CLASSIFICATION } \\
\text { OF REPORT } \\
\text { Unclassified }\end{array}$ & $\begin{array}{l}\text { 18. SECURITY CLASSIFICATION } \\
\text { OF THIS PAGE } \\
\text { Unclassified }\end{array}$ & $\begin{array}{l}\text { 19. SECURITY CLASSIFICATION } \\
\text { OF ABSTRACT } \\
\text { Unclassified }\end{array}$ \\
\hline
\end{tabular}

15. NUMBER OF PAGES 21

16. PRICE CODE

A03
20. LIMITATION OF ABSTRACT 